7 - Original Article

CLINICAL INVESTIGATION

\title{
Toll like receptors gene expression of human keratinocytes cultured of severe burn injury ${ }^{1}$
}

\author{
Sarita Mac Cornick, Silvana Aparecida Alves Corrêa de Noronha ${ }^{\mathrm{II}}$, Samuel Marcos Ribeiro de Noronha ${ }^{\mathrm{III}}$, Marcus V. B. Cezillo ${ }^{\mathrm{IV}}$, \\ Lydia Masako Ferreirav, Alfredo Gragnani ${ }^{\mathrm{II}}$
}

DOI: http://dx.doi.org/10.1590/S0102-86502014001700007

IFellow PhD degree, Division of Plastic Surgery, Department of Surgery, UNIFESP-EPM, Sao Paulo-SP, Brazil. Acquisition and interpretation of data; collection of study information; assistance with manuscript writing.

IIPhD, Post-doctoral student, Division of Plastic Surgery, Department of Surgery, UNIFESP-EPM, Sao Paulo-SP, Brazil. Acquisition and interpretation of data, collection of study information; manuscript writing; manuscript editing.

IIIPhD, Post-doctoral degree, Division of Plastic Surgery, Department of Surgery, UNIFESP-EPM, Sao Paulo-SP, Brazil. Acquisition and interpretation of data; collection of study information; assistance with manuscript writing.

${ }^{\mathrm{IV}}$ Graduate student, UNIFESP-EPM, Sao Paulo-SP, Brazil. Acquisition, analysis and interpretation of data; technical procedures; manuscript writing.

${ }^{\vee}$ Head and Full Professor, Plastic Surgery Division, UNIFESP, Researcher 1A-CNPq, Director Medicine III-CAPES, Brazil

${ }^{V} \mathrm{PhD}$, Associate Professor, Division of Plastic Surgery, Department of Surgery, Federal University of Sao Paulo, Paulista School of Medicine (UNIFESP-EPM), Brazil. Conception, design, intellectual and scientific content of the study; analysis and interpretation of data; manuscript writing; critical revision.

\section{ABSTRACT}

PURPOSE: To evaluate the expression profile of genes related to Toll Like Receptors (TLR) pathways of human Primary Epidermal keratinocytes of patients with severe burns.

METHODS: After obtaining viable fragments of skin with and without burning, culture hKEP was initiated by the enzymatic method using Dispase (Sigma-Aldrich). These cells were treated with Trizol ${ }^{\circ}$ (Life Technologies) for extraction of total RNA. This was quantified and analyzed for purity for obtaining cDNA for the analysis of gene expression using specific TLR pathways PCR Arrays plates (SA Biosciences).

RESULTS: After the analysis of gene expression we found that $21 \%$ of these genes were differentially expressed, of which $100 \%$ were repressed or hyporegulated. Among these, the following genes (fold decrease): HSPA1A (-58), HRAS (-36), MAP2K3 (-23), TOLLIP (-23), RELA (-18), FOS (-16), and TLR1 (-6.0).

CONCLUSIONS: This study contributes to the understanding of the molecular mechanisms related to TLR pathways and underlying wound infection caused by the burn. Furthermore, it may provide new strategies to restore normal expression of these genes and thereby change the healing process and improve clinical outcome.

Key words: Gene Expression. Burn. Toll Like Receptors. Human Keratinocytes. 


\section{Introduction}

The epidermis contains a basal layer of keratinocytes proliferation constant. These cells remain adhered to the underlying basement membrane. Periodically keratinocytes stop the cell cycle, stand out from the basement membrane and initiate a process of terminal differentiation as they move to the surface of the skin. This gradual process culminates in the formation of three distinct layers, the prickly, the granulosa and the cornea ${ }^{1}$.

Burns skin injuries are classified according to depth, surface thickness, with the superficial partial and deep thickness, and the total thickness ${ }^{2}$. Regarding the extent of the injuries, the total body surface area (TBSA) burned is classified as small, when up to $10 \%$ TBSA; medium when between 10 and 25\% TBSA; and large, when it affects $25 \%$ or more $\mathrm{TBSA}^{3-5}$.

The loss of the normal barrier function of the skin causes the most common pathological conditions associated with the infection are burning, heat loss, increased loss of water by evaporation and changes in the major interactive functions such as feel and appearance ${ }^{6,7}$.

Bacterial infection is a common complication in burn patients, the lack of primary barrier and also by immunosuppression and the presence of multiple foci of infection during the course of treatment may even lead to death. Method of invasive infection of the subcutaneous tissue plays an important role as related to surgery and infection of superficial wound infection ${ }^{8}$.

Inflammation is an important tool to promote epithelialization and wound healing caused by the burn factor. The beneficial effects of local inflammation include cleaning of cellular debris, protection against microbial agents, in addition to cell growth and proliferation. However, the extension of the acute inflammatory hinders the healing process in that the high level of cytokines, promotes the degradation of collagen, apoptosis of keratinocytes, and vascular compromise the production of oxygen free radicals ${ }^{9}$.

The Toll-like receptors (TLR) are important cells of the innate immune system that recognize antigens. The innate immune system of the host cells are able to recognize patterns associated with pathogen molecules (PAMPs). The first TLR in mammals was described in 1997, there are currently 13 types described ${ }^{10}$, but are 10 TLRs identified in humans to date ${ }^{11}$. Activation of these receptors induces the production of inflammatory cytokines and chemokines $^{12,13}$

TLR4 recognizes predominantly lipopolissarídeo (LPS) endotoxin called component of gram-negative bacteria ${ }^{14}$. Since the lipopeptide TLR2 recognizes the exogenous ligand gram-positive bacteria $^{15}$.
After the link between the exogenous and TLR2 ligand, receptor dimerization occurs and conformational changes. The signaling pathways activated by these receptors include the gene of the myeloid differentiation primary response (88) (MYD88), the MyD88-dependent and TIR-domain adapter inducing interferon- $\beta$ (TRIF-dependent). The via MyD88 is used by all TLRs except for TLR3, whose activation results in activation of transcription factors such as nuclear factor kappaB (NF-kappaB), the activator protein 1 (AP-1). Upon activation of these factors, numerous pro-inflammatory cytokines are produced by cells, such as interleukins 6 and $1 \beta$ (IL-6, IL-1 $)$ ) and tumor necrosis factor alpha $(\mathrm{TNF}-\alpha)^{16}$.

The lack of data in the literature and the functional interaction of signaling pathways related to TLRs on keratinocytes and dermal fibroblasts in burn patients, this issue is worthy of being explored in burns that attacked the body surface.

Therefore, our aim is to evaluate the expression of 84 genes related to the signaling pathway of Toll-like receptors by PCR Array in cultured epidermal keratinocytes from burned patients.

\section{Methods}

\section{Experimental design}

The project was submitted by the Ethics Committee of Federal University of Sao Paulo (UNIFESP) and approved in November $9^{\text {th }}, 2012$ (146.468).

The present study design is experimental, in vitro, using donated burn patients tissues. It is observational, analytic, controlled and conduced in a single center. All the patients included in this study have read and signed the Free and Clarified Contentment Term.

\section{Patients}

The patients recruited to this study were burn victims (Table 1) admitted in the Burns Treatment Unit, Plastic Surgery Division, Federal University of São Paulo, University Hospital.

TABLE 1 - Data (n, age, gender, mean \% TBSA) of burned patients included in the study.

\begin{tabular}{cccc}
\hline Group & $\begin{array}{c}\text { Age Medium } \\
\text { (years) }\end{array}$ & Gender & $\begin{array}{c}\text { SCQ Medium } \\
(\%)\end{array}$ \\
\hline Severe Burn & 31.5 & $3 \mathrm{M}$ & 32 \\
& & $1 \mathrm{~F}$ & \\
\hline
\end{tabular}

F, female; M, male. 
The control group comprised healthy, non-smoking donors submitted to aesthetic plastic surgery. The first is a 38 years old female who underwent breast lift surgery; the second patient was a 32 years old female who underwent abdominoplasty.

All of them fit in the inclusion criteria.

\section{Inclusion, exclusion and non-inclusion criteria}

Inclusion criteria for the study were patients of both genders, over 18 years old, who agreed to participate and signed a consent form, being hospitalized in Burns Unit and requiring surgery. A criterion was added to the group with large burns: having deep partial thickness or full thickness burns affecting between $25 \%$ and $50 \%$ of total body area surface (TBSA) or which require partial skin graft in $10 \%$ TBSA. To the control group was included the criterion of not having previous diseases, not smoking, and performing aesthetic surgery.

Patients who had previous skin diseases, such as psoriasis and similar, superficial skin lesions or illnesses that might interfere directly in the inflammatory process, as rheumatologic diseases in general were not included.

Exclusion criteria were contamination of the culture flasks, low proliferation rate without achieving confluence of $80 \%$ of the cells in the culture flasks, insufficient quantity of extracted RNA that prevents the evaluation of patient data or non-viability of the extracted material.

\section{Surgical procedure}

The skin samples used in this study were obtained by the usual surgical procedure for burn patient care in our Burns Unit. Debridement of dead tissue from a patient with full or partial thickness burns was realized 4 days after the burn; the healthy skin around the burn lesion, which is normally collected and discarded, was destined to culture in our laboratory.

\section{Keratinocyte culture}

Keratinocytes derived from a skin fragment of a burn patient were isolated and cultured according to the standard method, adapted in our laboratory with changes as described below $^{17,18}$.

In a $60 \mathrm{~mm}$ culture plate, the skin fragment was placed and sectioned into small pieces with sizes of approximately 0.5 $\mathrm{cm}^{3}$. Those fragments were placed in a $50 \mathrm{ml}$ sterile tube with $30 \mathrm{ml}$ of dispase (Boeringer Mannheim, Indianapolis, IN) and kept refrigerated at $4^{\circ} \mathrm{C}$ until the next day, totaling 15 hours of action of dispase. After this period, each epidermal fragment was gently detached from the dermis with forceps; the epidermis was intended for isolation of keratinocytes ${ }^{18}$.

\section{Total RNA extraction}

Each cell type was separately homogenized using Trizol $^{\mathrm{TM}}$ reagent (Invitrogen, Foster City, CA) following the manufacturer's instructions. After complete dissociation of nucleoprotein complexes, phase separation was achieved with chloroform and centrifugation. The precipitated RNA from the aqueous phase was washed with $75 \%$ ethanol. The RNA was dried and dissolved in RNase-free water. Total RNA was then purified with Qiagen RNeasy MiniKit (Qiagen, Valencia, CA) and submitted to DNAse treatment using the RNase-free DNase Set (Qiagen Inc., Valencia, CA, USA). The amount and quality of the extracted RNA were assessed by spectrophotometry using NanoDrop v3.3.0 (NanoDrop Technologies Inc., Rockland, DE) and capillary electrophoresis using Bioanalyzer 2100 (Agilent Technologies Inc., Palo Alto, CA, USA).

\section{qPCR array}

The total RNA $(1.0 \mu \mathrm{g})$ per plate/array from each pool of patient was used for synthesis of cDNA. Samples were treated with buffer coming from the kit and reverse transcription reactions were performed using the RT2 First Strand Kit from SABiosciences (Qiagen Company), according to the manufacturer's protocol. qPCR Array was performed using the RT2 Profiler ${ }^{\mathrm{TM}}$ PCR array of SABiosciences (http://www.sabiosciences.com/ArrayList.php).

For each patient 84 genes were examined for relevant human genes involved in the Toll Like Receptors pathway (PAHS-018Z). Amplification, data acquisition, analysis curves were performed on an ABI Prism 7500FAST Sequence Detection System (Applied Biosystems, Foster City, CA). In each turn, each gene was checked for efficiency, and minimum and maximum threshold curve pattern. To ensure accurate comparisons between curves the same threshold were established for all genes and races. Three genes were used as internal control and the average $\mathrm{Ct}$ value were used to standardize gene expression (2-CT change table) and determine the difference between groups. Gene expression was considered upregulated or downregulated when the difference was more than two times.

\section{Statistical analysis}

The statistical parameters and the data analysis were performed by the RT2 Profiler PCR Array data analysis version 3.5 
(http://pcrdataanalysis.sabiosciences.com/pcr/arrayanalysis.php). For the analysis it was considered significant the fold change/fold regulation that presented a $\mathrm{p}$ value less than 0.05 .

\section{Results}

After the expression analysis of the 84 studied genes for each pathway, we observed, for Toll Like Receptor pathway, that $21 \%$ of these genes were differentially expressed, among these $100 \%$ were down-regulated (Figures 1 and 2).
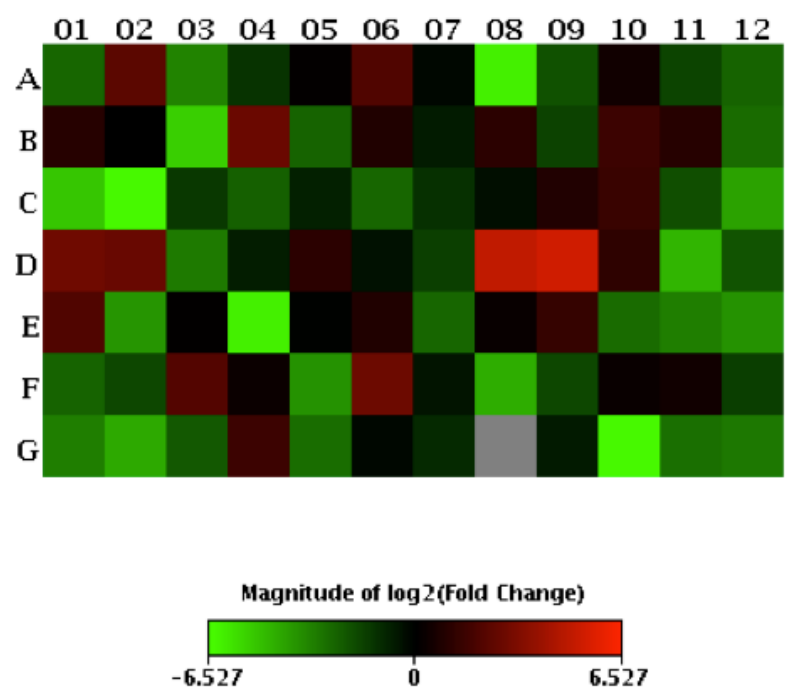

FIGURE 1 - Heat Map for Toll Like Receptor pathway from cultured keratinocytes from burned patients. In red, up-regulated genes; in green, down regulated genes; and in black, genes not regulated.

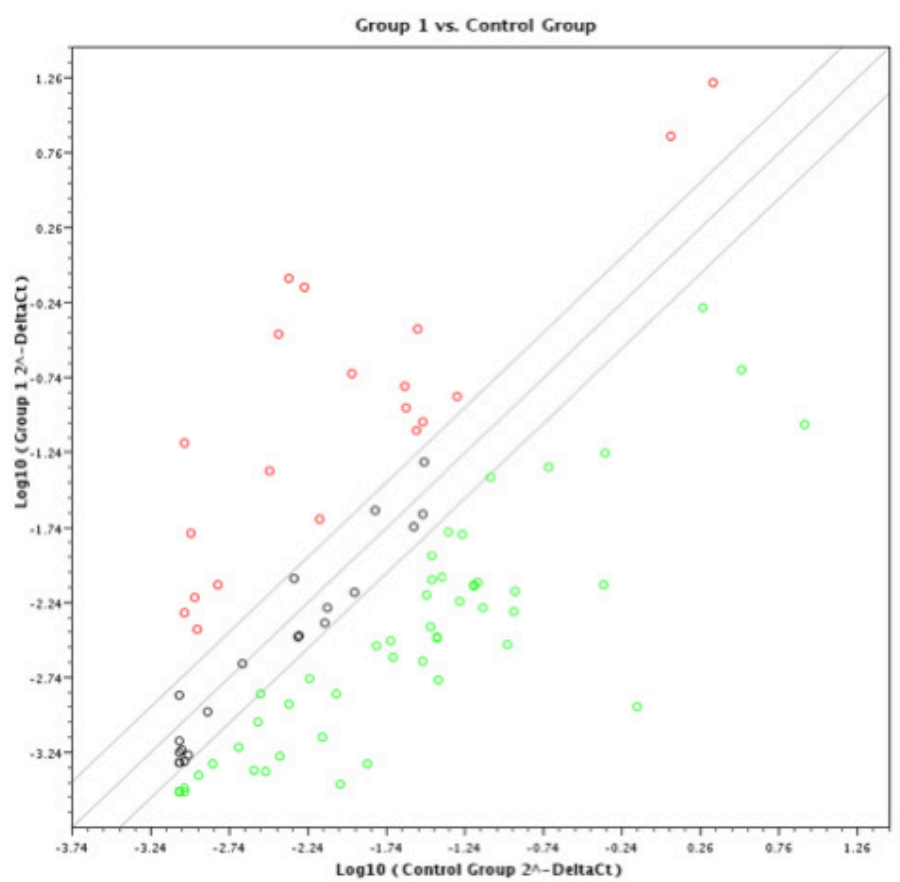

FIGURE 2 - Scatter Plot for Toll Like Receptor pathway from cultured keratinocytes from burned patients. In red, up-regulated genes; in green, down regulated genes; and in black, genes not regulated.
Among differentially expressed genes, we highlight the seven most hypo expressed genes, that were: HSPA1A (58 times), HRAS (36 times), MAP2K3 (23 times), TOLLIP (23 times), RELA (18 times), FOS (16 times), and TLR1 (6.0 times) (Figure 3).

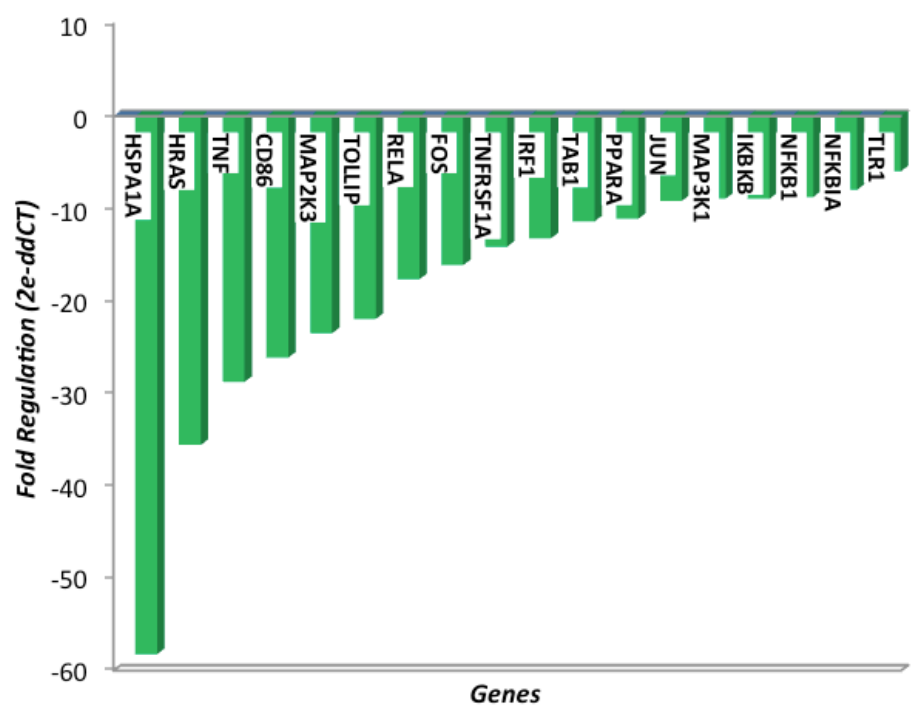

FIGURE 3 - Hypoexpressed genes for Toll Like Receptor pathway from cultured keratinocytes from burned patients.

\section{Discussion}

In order to update the literature on the gene expression of Toll Like receptors in the skin of burned patients, we performed extensive search, however, did not return any results to this topic. Overwhelmingly, the articles dealing separately genes involved in this system, in addition, in animal models, and a few times were performed protein instead gene analyzes. Below we discuss some important genes that presented with decreased expression in patients with severe burns in relation to controls.

Heat shock 70kDa protein 1A (HSPA1A) gene encodes a $70 \mathrm{kDa}$ heat shock protein which is a member of the heat shock protein 70 family. In conjunction with other heat shock proteins, this protein stabilizes existing proteins against aggregation and mediates the folding of newly translated proteins in the cytosol and in organelles. To better understand the cellular and molecular responses to overexposure to millimeter waves, alterations in the gene expression profile and histology of skin after exposure to $35 \mathrm{GHz}$ radiofrequency radiation were investigated. Upregulation of Hspala at $24 \mathrm{~h}$ by $35 \mathrm{GHz}$ millimeter-wave exposure was confirmed by real-time RT-PCR. The results indicated that prolonged exposure to $35 \mathrm{GHz}$ millimeter waves causes thermally related stress and injury in skin while triggering repair processes involving inflammation and tissue matrix recovery ${ }^{19}$. 
Harvey rat sarcoma viral oncogene homolog(HRAS) gene belongs to the Ras oncogene family, whose members are related to the transforming genes of mammalian sarcoma retroviruses. The products encoded by these genes function in signal transduction pathways. Mutations in this gene are associated with melanoma caused by sun exposure ${ }^{20}$.

Mitogen-activated protein kinase 3 (HRAS) gene is a dual specificity protein kinase that belongs to the MAP kinase family. This kinase is activated by mitogenic and environmental stress, and participates in the MAP kinase-mediated signaling cascade. It phosphorylates and thus activates MAPK14/p38MAPK. This kinase can be activated by insulin, and is necessary for the expression of glucose transporter. Expression of RAS oncogene is found to result in the accumulation of the active form of this kinase, which thus leads to the constitutive activation of MAPK14, and confers oncogenic transformation of primary cells. It is involved in the protective response to cellular injury by hypoxia in lung epithelial ${ }^{21}$.

Therefore, HSPA1A, HRAS, and HRAS can be relevant to repair processes. In our results we observed decrease in expression of these genes that can implicate a worsening in the repair of the injury caused by severe burn.

Toll interacting protein (TOLLIP) gene encodes an ubiquitin-binding protein that interacts with several Toll-like receptor (TLR) signaling cascade components. The encoded protein regulates inflammatory signaling and is involved in interleukin-1 receptor trafficking and in the turnover of IL1Rassociated kinase. Polymorphisms in this gene are associated with atopic dermatitis ${ }^{22}$.

NF-kappa-B is a ubiquitous transcription factor involved in several biological processes. It is held in the cytoplasm in an inactive state by specific inhibitors. Upon degradation of the inhibitor, NF-kappa-B moves to the nucleus and activates transcription of specific genes. NF-kappa-B is composed of NFKB1 or NFKB2 bound to REL, RELA, or RELB. The most abundant form of NF-kappa-B is NFKB1 complexed with the product of this gene, RELA (v-rel avian reticuloendotheliosis viral oncogene homolog A). RELA has a regulating epidermal proliferation and homeostasis and a profibrogenic role for in the skin, and identify a link between epidermal RELA expression and systemic sclerosis. Modulating the actions of these subunits could be beneficial for treating hyperproliferative or fibrogenic diseases of the skin ${ }^{23}$. This gene is repressed in severe burn, then that function can be altered.

FBJ osteosarcoma oncogene (FOS) gene responds to extracellular stimuli and undergoes robust but transient transcriptional activation. C-fos can be regarded as a target in identifying electrical injury ${ }^{24}$. An animal model of radiationinduced skin ulcers in rats irradiated with 35 to 55 Gy y-rays it was established. The results suggested that the changes in c-fos and $\mathrm{Rb}$ proteins may be related to the poor healing of radiationinduced skin ulcers ${ }^{24}$.

Toll Like receptor 1(TLR1) gene is a member of the Toll-like receptor (TLR) family which plays a fundamental role in pathogen recognition and activation of innate immunity. TLRs are highly conserved from Drosophila to humans and share structural and functional similarities. They recognize pathogen-associated molecular patterns (PAMPs) that are expressed on infectious agents, and mediate the production of cytokines necessary for the development of effective immunity. Polymorphisms in TLR1 are associated with increased susceptibility to complicated skin and skin structure infections. For TLR1, impaired proinflammatory cytokine production due to the polymorphism is most likely the mechanism mediating this effect ${ }^{25}$.

Nuclear TLR1 staining was observed in the upper layers of both nonlesional and lesional psoriatic epidermis, but not in that of normal skin. These findings suggest that TLRs expressed by epidermal keratinocytes constitute part of the innate immune system of the skin. The relevance of altered keratinocyte TLR expression in psoriasis remains to be determined ${ }^{26}$.

Therefore, we can observe that the genes above related are implicated in restoration to injury or wound of skin and others organs. And the repressed expression of these genes, that we saw in ours results, can mean a worsening in function of the skin as an organ protective immune.

\section{Conclusion}

This study contributes to the understanding of the molecular mechanisms related to TLR pathways and underlying wound infection caused by the burns. Furthermore, it may provide new strategies to restore normal expression of these genes and thereby change the healing process and improve clinical outcome.

Wherefore, further studies in the future about these genes could contribute to the development of new drugs that can restore patients with damage skin burns faster and more effectively.

\section{References}

1. Pincelli C, Marconi A. Keratinocyte stem cells: friends and foes. J Cell Physiol. 2010;225(2):310-5.

2. Rangel MF, Pereira APJT. Atendimento inicial e definitivo do grande queimado. J Bras Med. 2007;92(2):20-2.

3. Vale ECS. Initial management of burns: approach by dermatologists. An Bras Dermatol. 2005;80(1):9-19. 
4. Evers LH, Bhavsar D, Mailander P. The biology of burn injury. Exp Dermatol. 2010;19:777-83.

5. Degim Z, Celebi N, Alemdaroglu C, Deveci M, Ozturk S, Ozogul C. Evaluation of chitosan gel containing liposome-loaded epidermal growth factor on burn wound healing. Int Wound J. 2011;8:343-54.

6. Keck M, Herndon DH, Kamolz LP, Frey M, Jeschke MG. Pathophysiology of burns. Wien Med Wochenschr. 2009;159(1314):327-36.

7. Rezaei E, Safari H, Naderinasab M, Aliakbarian H. Common pathogens in burn wound and changes in their drug sensitivity. Burns. 2011;37(5):805-7.

8. Spanholtz TA, Theodorou P, Amini P, Spilker G. Severe burn injuries: acute and long-term treatment. Dtsch Arztebl Int. 2009;106(38):607-13.

9. Shupp JW, Nasabzadeh TJ, Rosenthal DS, Jordan MH, Fidler P, Jeng JC. A review of the local pathophysiologic bases of burn wound progression. J Burn Care Res. 2010;31(6):849-73.

10. Nicotra L, Loram LC, Watkins LR, Hutchinson MR. Toll Like receptors in chronic pain. Exp Neurol. 2012;234(2):316-29.

11. Schwacha MG, Zhang Q, Rani M, Craig T, Oppeltz RF. Burn enhances Toll like receptor induce responses by circulating leukocytes. Int J Clin Exp Med. 2012;5(2):136-44.

12. West AP, Koblansky AA, Ghosh S. Recognition and signaling by toll-like receptors. Annu Rev Cell Dev Biol. 2006;22:409-36.

13. Drage MG, Pecora ND, Hise AG, Febbraio M, Silverstein RL, Golenbock DT, Boom WH, Harding CV. TLR2 and its coreceptors determine responses of macrophages and dendritic cells to lipoproteins of Mycobacterium tuberculosis. Cell Immunol. 2009;258:29-37.

14. Tsan MF, Gao B. Endogenous ligands of Toll-like receptors. J Leukoc Biol. 2004;76:514-9.

15. Kawai T, Akira S. TLR signaling. Semin Immunol. 2007;19:24-32.

16. Nicotra L, Loram LC, Watkins LR, Hutchinson MR. Toll Like receptors in chronic pain. Exp Neurol. 2012;234(2):316-29.

17. Green H, Kehinde O, Thomas J. Growth of cultured human epidermal cells into multiple epithelia suitable for grafting. Proc Natl Acad Sci USA. 1979; 76 (11):5665-8.

18. Gragnani A, Morgan JR, Ferreira LM. Differentiation and barrier formation of a cultured composite skin graft. J Burn Care Rehabil. 2002;23(2):126-31.

19. Millenbaugh NJ, Roth C, Sypniewska R, Chan V, Eggers JS, Kiel JL, Blystone RV, Mason PA. Gene expression changes in the skin of rats induced by prolonged $35 \mathrm{GHz}$ millimeter-wave exposure. Radiat Res. 2008 Mar;169(3):288-300.

20. Jiveskog S, Ragnarsson-Olding B, Platz A, Ringborg U. N-ras mutations are common in melanomas from sun-exposed skin of humans but rare in mucosal membranes or unexposed skin. J Invest Dermatol. 1998 Nov;111(5):757-61

21. Powell CS, Wright MM, Jackson RM. p38mapk and MEK1/2 inhibition contribute to cellular oxidant injury after hypoxia. Am J Physiol Lung Cell Mol Physiol. 2004 Apr;286(4):L826-33.

22. Schimming TT, Parwez Q, Petrasch-Parwez E, Nothnagel M, Epplen JT, Hoffjan S. BMC Association of toll-interacting protein gene polymorphisms with atopic dermatitis. Dermatol. 2007 Mar 16;7:3.
23. Fullard N, Moles A, O’Reilly S, van Laar JM, Faini D, Diboll J, Reynolds NJ, Mann DA, Reichelt J, Oakley F. The c-Rel subunit of $\mathrm{NF}-\kappa \mathrm{B}$ regulates epidermal homeostasis and promotes skin fibrosis in mice. Am J Pathol. 2013 Jun;182(6):2109-20.

24. Ghandour NM, Refaiy AE, Omran GA. Cardiac histopathological and immunohistochemical changes due to electric injury in rats. J Forensic Leg Med. 2014 Mar;23:44-8.

25. Gu Q, Gao Y, Li Y, Yang Z, Zhou J, Wang X, Wang D, Zhao P. Overexpression of $\mathrm{c}$-fos and $\mathrm{Rb}$ proteins in radiation-induced skin ulcers. J Environ Pathol Toxicol Oncol. 1999;18(4):309-12.

26. Stappers $M H$, Thys $Y$, Oosting M, Plantinga TS, Ioana M, Reimnitz P, Mouton JW, Netea MG, Joosten LA, Gyssens IC. TLR1, TLR2, and TLR6 Gene Polymorphisms Are Associated With Increased Susceptibility to Complicated Skin and Skin Structure Infections. J Infect Dis. 2014 Jul 15;210(2):311-8.

27. Baker BS, Ovigne JM, Powles AV, Corcoran S, Fry L. Normal keratinocytes express Toll-like receptors (TLRs) 1, 2 and 5: modulation of TLR expression in chronic plaque psoriasis. Br J Dermatol. 2003 Apr;148(4):670-9.

\section{Acknowledgement}

To Sao Paulo Research Foundation (FAPESP) for Research Grants number 2011/12945-4 and 2013/10.905-0.

\section{Correspondence:}

Alfredo Gragnani

Rua Napoleão de Barros, $715 / 4^{\circ}$ andar

04024-002 São Paulo - SP Brasil

Tel.: (55 11)5576-4118 / 5579-4933

Fax: (55 11)5571-6579

alfredogf@ig.com.br

${ }^{1}$ Research performed at Division of Plastic Surgery, Department of Surgery, Paulista School of Medicine (EPM), Federal University of Sao Paulo (UNIFESP), Brazil. 